\title{
Modelled versus observed open cut performance in weak transition rock: the Dubbo Quarry case study
}

\author{
D Trani GHD Pty Ltd and University of Wollongong, Australia \\ J Hellmuth GHD Pty Ltd, Australia \\ J Thompson GHD Pty Ltd, Australia
}

\begin{abstract}
As open pit mining advances, the importance of ensuring the geotechnical slope stability of the cut face becomes critical particularly when transitioning within a weak rock zone. One of the essential components of day-to-day operations is the monitoring of cut geometries which plays a key role in assisting geotechnical engineers and mine operators in maintaining mine safety and production schedules. This paper presents a case study of a basalt quarry site in southwest Dubbo NSW wherein mining of the previously blasted bench of the more competent, fine-grained basalt was restricted due to the likely risk of collapse of the adjacent remaining cut face comprising weak, altered basalt that was believed to have been steeply deposited against a lithic sandstone. Spatial analysis of deformation point measurement data derived from traditional geodetic prism monitoring was performed. A simplified wedge stability analysis via limit equilibrium method was then carried out based on likely combination of shear strength parameters that could reasonably suit the observed gradual geometric changes of the cut face. A review of the reported geometry following the actual collapse of the cut face indicated a broad agreement with the modelling outcome, which in turn revealed that the adopted simplified analytical methodology based on observed deformations, in combination with a good understanding of the geologic setting, can be used to estimate likely performance of cut faces in weak transition rocks.
\end{abstract}

Keywords: wedge stability, prism monitoring, limit equilibrium, geologic setting

\section{Introduction}

Rock slope performance assessments, on both natural and man-made rock exposures, include measurements of slope geometry and observation of past failure mechanisms. In open pit mines and quarries, for example, assessing highwall performance involves measurements of achieved bench parameters, including effective batter angle, back-break, bench height and berm width. These parameters are compared to the design in order to validate assumptions which are generally based on limited drillhole data and rock exposure (Mathis 2007, 2011; Read \& Stacey 2009). Systematic documentation and evaluation of the performance of highwalls is an important component of any open pit slope assessment program. During early mine excavation stages, performance analysis of test benches should provide validation of the design model. Slope performance assessment will also be part of the monitoring program during the mine life, and for pit expansion projects.

The purpose of this paper is to report on the case study of a basalt quarry site in southwest Dubbo NSW wherein mining of the previously blasted bench of the more competent, fine-grained basalt was restricted due to the likely risk of collapse of the adjacent remaining cut face comprising weak, altered basalt that was believed to have been steeply deposited against a lithic sandstone. Spatial analysis of deformation point measurement data derived from traditional geodetic prism monitoring was performed. A simplified wedge stability analysis via limit equilibrium methods was then carried out based on likely combination of shear strength parameters that could reasonably suit the observed gradual geometric changes of the cut face. 


\section{$2 \quad$ Study area and methodology}

\subsection{Geological setting}

Dubbo Quarry is primarily a basalt quarry located to the southwest of Dubbo, NSW. According to the 2000 Dubbo 1:100,000 Geological Map (Sheet 8633), the quarry is located within a Tertiary alkali basalt (Tb) unit, and adjacent to Jurassic Purlawaugh Formation lithic quartz sandstone (Ju), both partially overlain by Quaternary alluvial sediments. It is postulated that the basalt deposition is due to lava flow into an existing river channel. This basalt appears to be composed of two stages, a vuggy and sometimes ropy, altered basalt, and a more competent, fine-grained basalt that is the main ore targeted by the quarry. The altered basalt is directly adjacent to the lithic sandstone, and a chilled margin may be observed at the contact zone. The general location of the site and the underlying geological setting is presented in Figure 1.

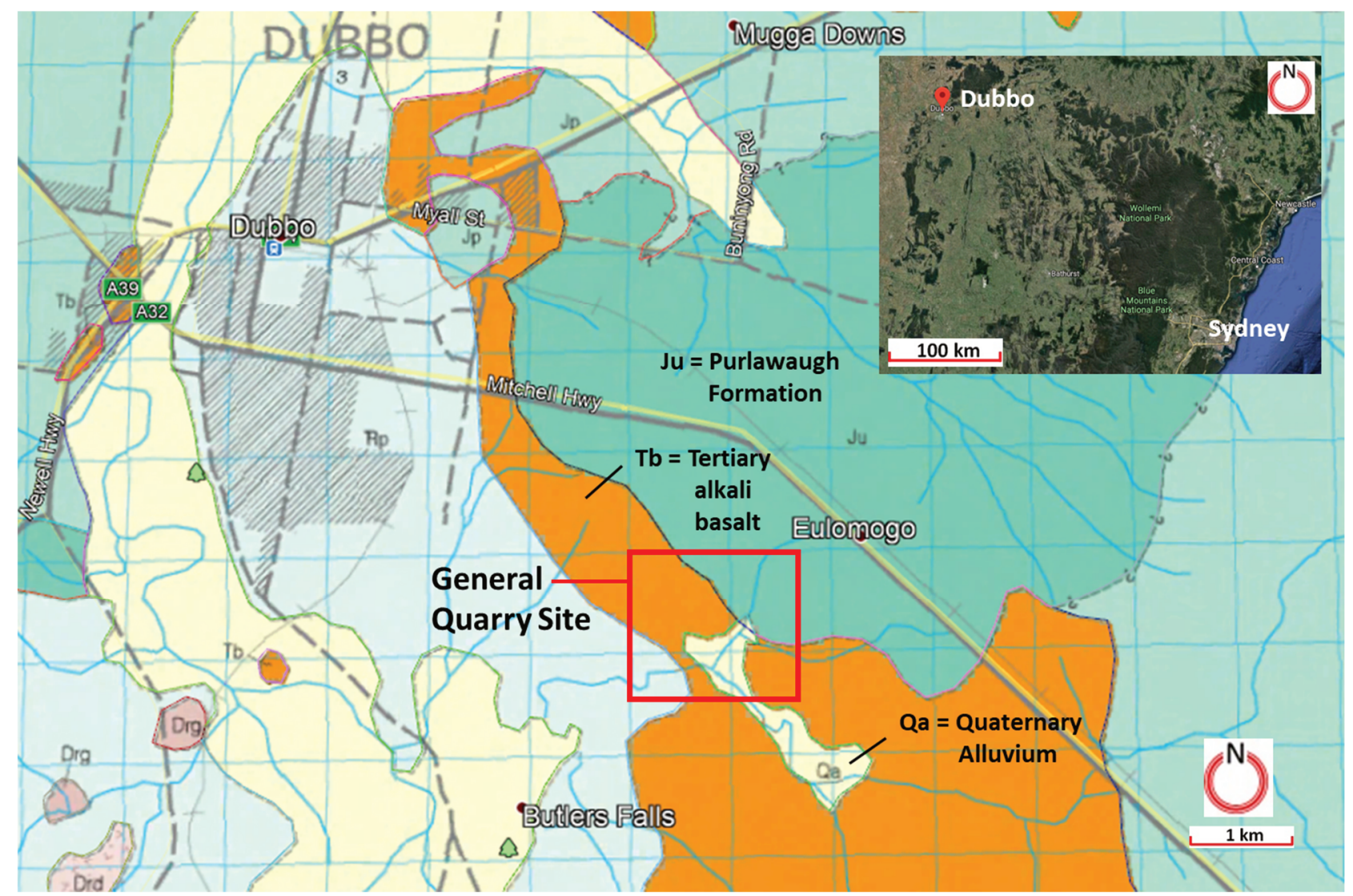

Figure 1 General quarry site location in Dubbo NSW

\subsection{Project understanding}

The current eastern highwall of the quarry has been developed over two benches. The first bench was approximately 8-12 $\mathrm{m}$ in height and was blasted and mined in two production shots; first the northern half and then the southern half. The second bench (approximately $8 \mathrm{~m}$ in height) was then blasted with a 3-5 $\mathrm{m}$ wide berm. This second bench was blasted in a single production shot and mining began at the southern end. This second bench is expected to be the final cut along this eastern highwall. A sketch of the generalised geological section of the exposed cutting on the eastern side of the quarry is presented in Figure 2. 


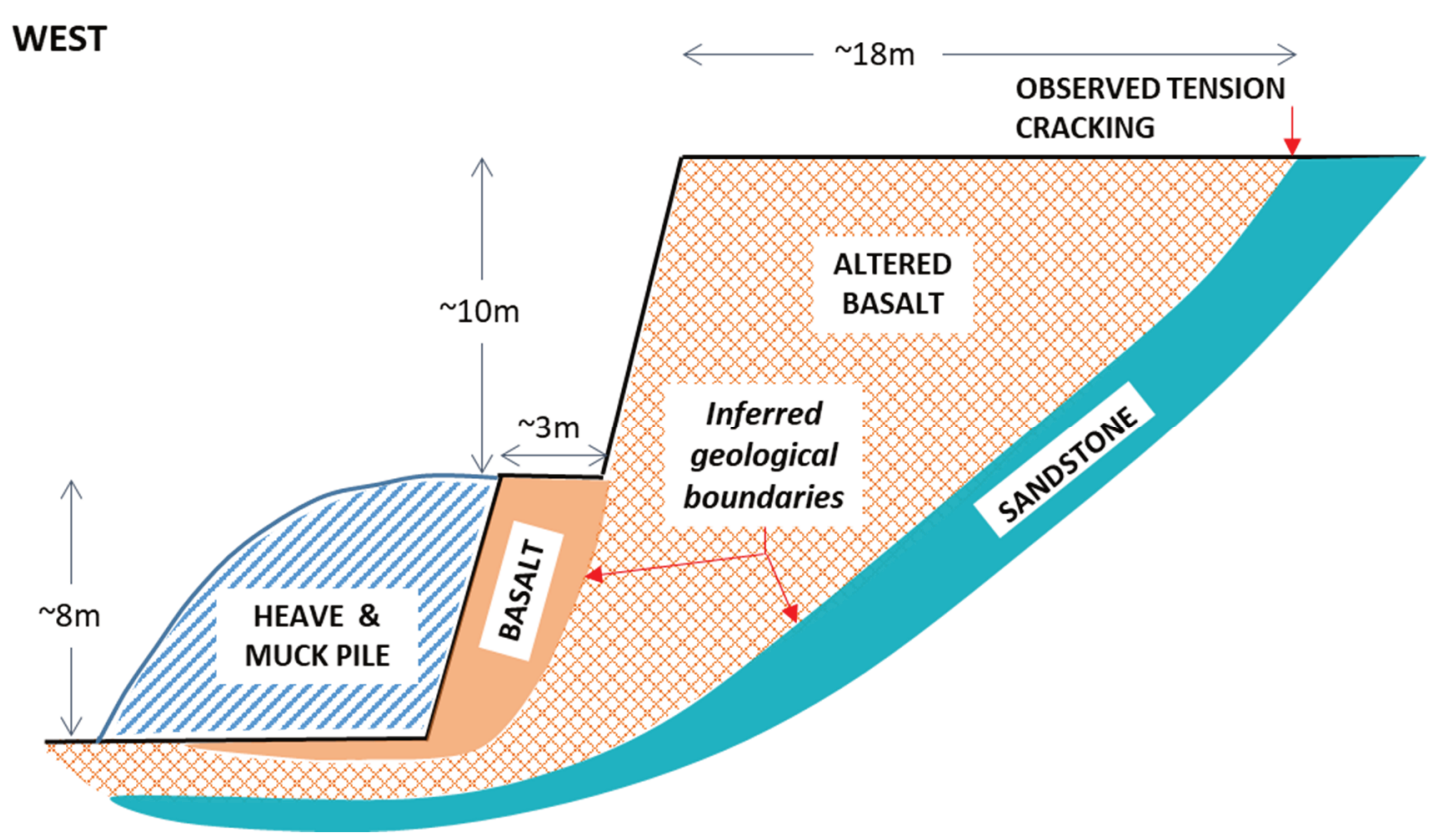

Figure 2 Generalised geological cross-section of the exposed cutting on the eastern side of the quarry

During mining of the second bench around the end of October 2018, cracks were noted by the pit supervisor as forming approximately $18 \mathrm{~m}$ behind the crest of the eastern highwall. These cracks were not noted during the blasting or mining of the first bench, nor the blasting of the second bench. It was surmised that these cracks were potentially due to a large-scale circular or translational-planar failure of the upper part of the highwall. In response, the quarry manager set up a geodetic prism monitoring regime adjacent to the line of cracking. Mining of the blasted material was also restricted to the southern end of the shot, away from the area directly beneath the cracks. Geotechnical advice was then sought regarding slope instability assessment and ground conditions behind the highwall.

\subsection{Prism monitoring}

Nine prisms and three backsights were set up at intervals along the line of cracking, which was supposed to be the back scarp of a potential failure. The general location of the prism monitoring set-up is shown in Figure 3. These prisms were monitored at regular intervals, initially fortnightly then increasing to twice weekly over the course of three months. The prism data were plotted on graphs which showed the changeover time in recorded Easting, Northing and Height above a reference level. The change in these fixed points was interpreted to represent movement of the prism in three-dimensional space. Trends associated with these changes were used to infer development of a highwall failure. Trigger levels for change per measurement in Easting, Northing and Level were also set, so that significant movements could be flagged for attention.

During the course of the monitoring, a trend of movement to the west was noted for five of the nine prisms, with an acceleration in movement during the fortnight before the failure occurred. A smaller magnitude of movement was also noted towards the south and downwards for these prisms. This provided information regarding both the increasing likelihood of failure, as well as the mode of failure. The recorded total movements from some select prisms are presented in Figure 4.

Monitoring was undertaken at the same time each day (mid-morning) to reduce areas introduced by changes in ambient temperature. However, it was observed that hotter days showed a greater change in absolute positions recorded during the prism monitoring. 


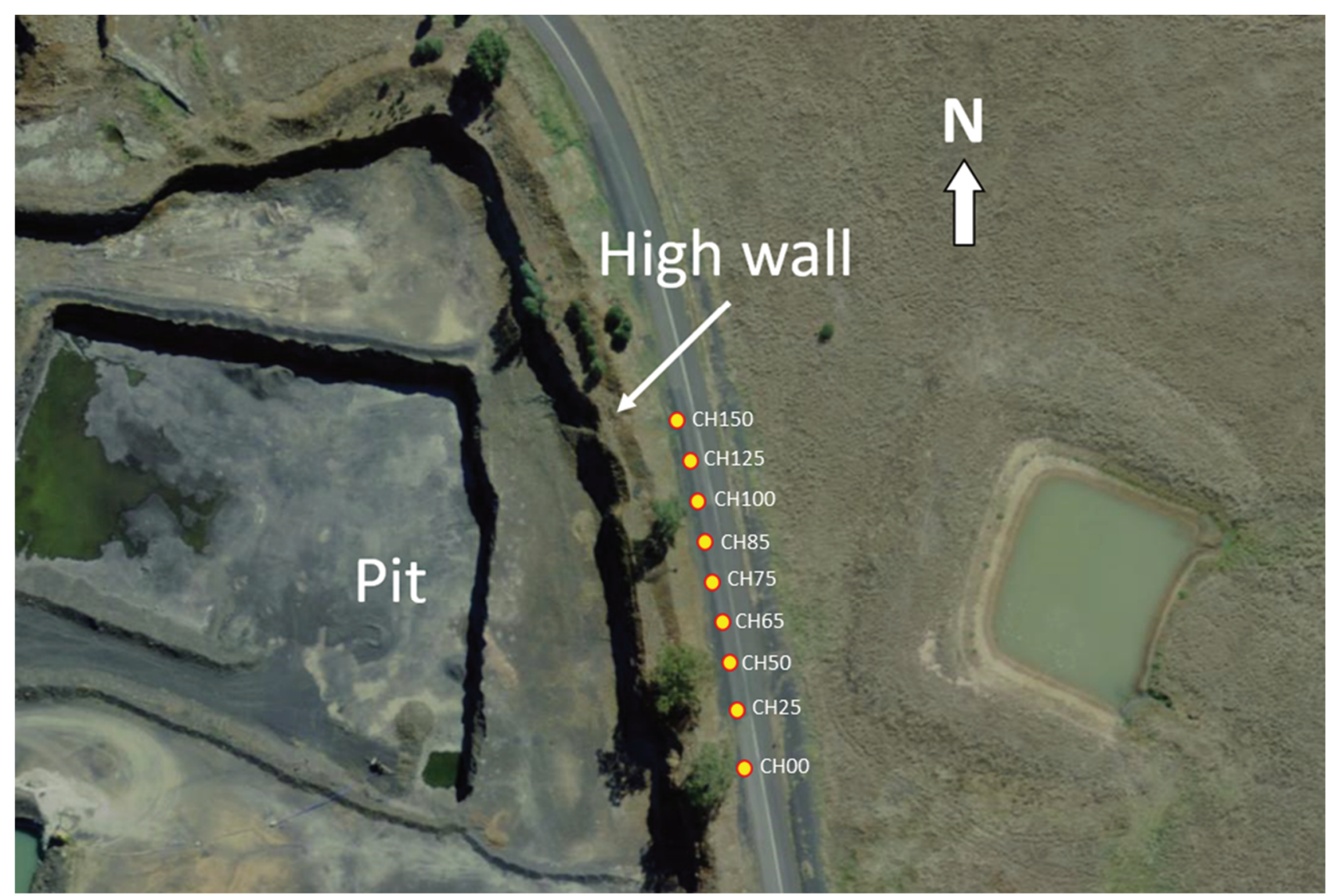

Figure 3 Prism monitoring set-up (approximate) shown on an aerial view of the highwall pre-failure

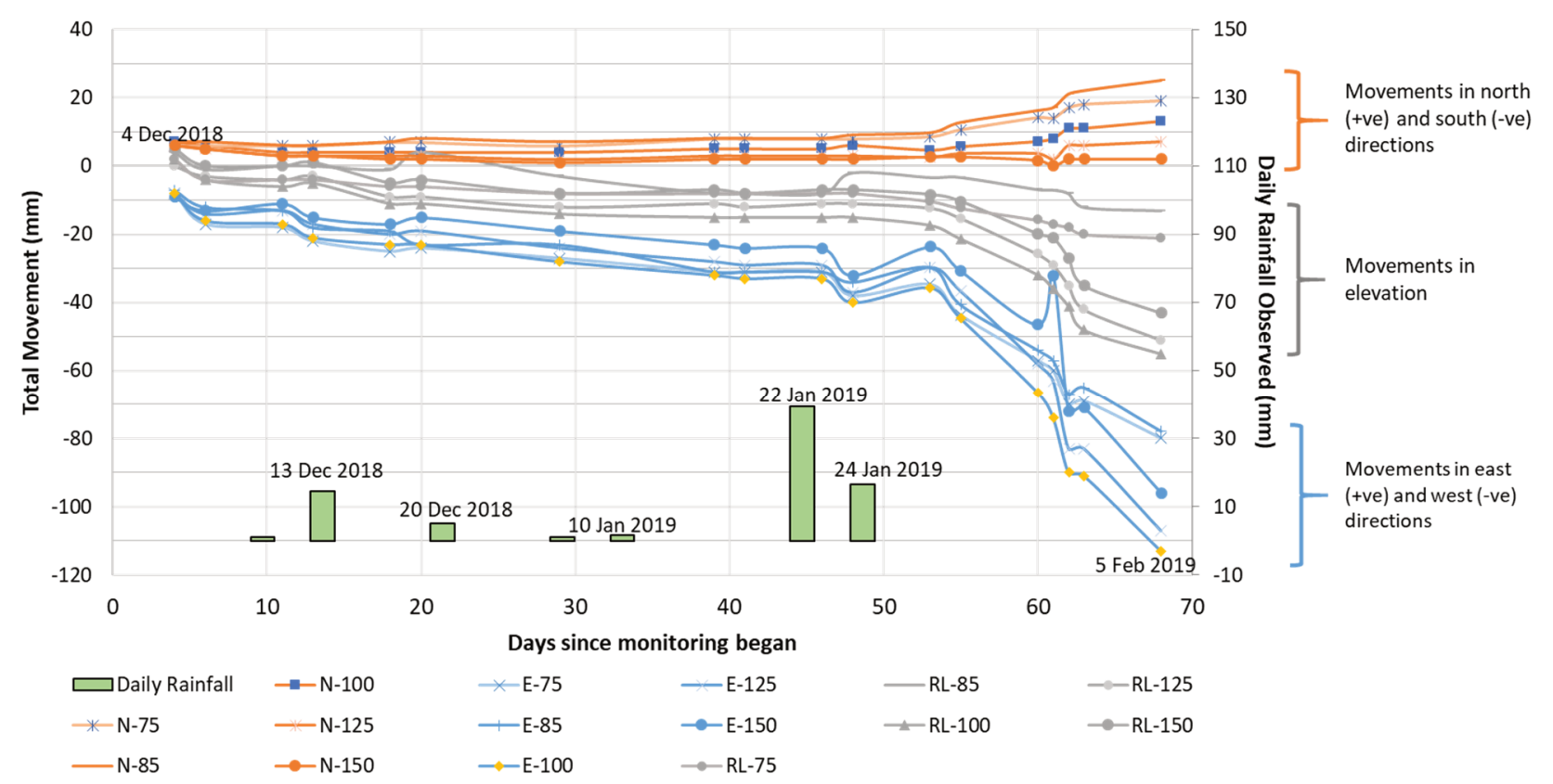

Figure 4 Movements as recorded from the installed prisms over time $(\mathrm{N}=$ northing, $\mathrm{RL}=$ reduced level, $\mathrm{E}=$ easting, $\# \#=$ chainage as represented in Figure 3 ) 


\subsection{Engineering geological mapping}

Site observations were made onsite on 15 January 2019. During the site inspection, the cracks behind the crest of the east wall were observed including:

- At approx. chainage $100 \mathrm{~m}$, cracking was observed to be up to $20 \mathrm{~mm}$ wide and up to $300 \mathrm{~mm}$ deep. Wash out of the edge of the crack was observed, due to recent rainfall. Cracking extended into a nearby windrow.

- At approx. chainage $150 \mathrm{~m}$, cracking was observed to be up to $30 \mathrm{~mm}$ wide and up to $600 \mathrm{~mm}$ deep.

- At approx. chainage $168 \mathrm{~m}$, cracking was observed to be up to $15 \mathrm{~mm}$ wide and up to $50 \mathrm{~mm}$ deep.

- At approx. chainage 50 to $75 \mathrm{~m}$, cracking appeared to be finer. This was corroborated by prism monitoring which shows relatively minimal movement in these prisms.

The cracks were generally observed to be between 5 to $18 \mathrm{~m}$ behind the crest of the east wall, and were generally subparallel to the crest. A typical photograph of the tension cracks along the asphalt sealed access road is shown in Figure 5.

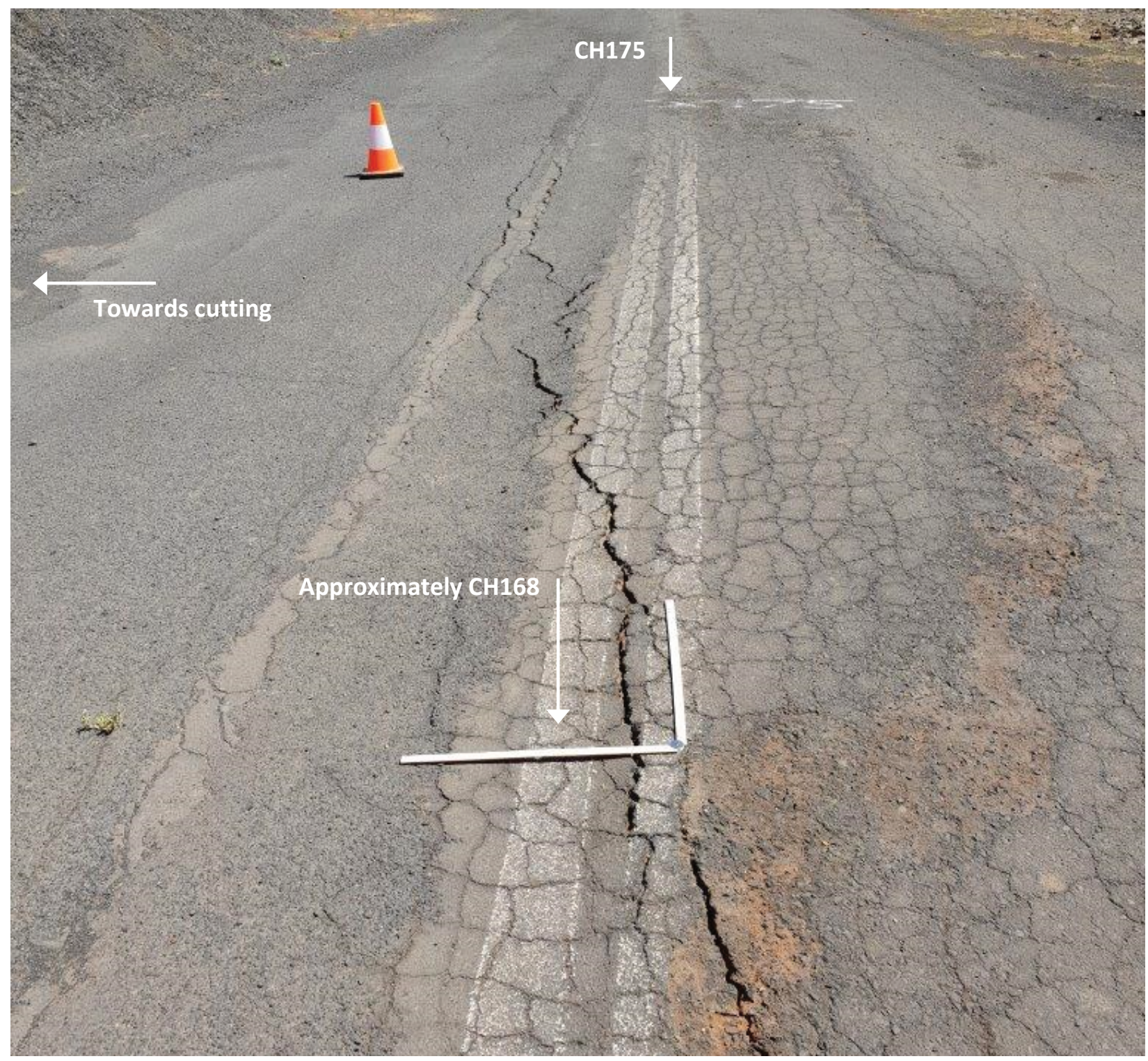

Figure 5 Cracking within asphalt access road behind eastern highwall (facing north) 
When observed from the floor, the eastern highwall was generally composed of the altered basalt with some lenses of competent basalt still upon the face. In the area where cracking was observed to have moved furthest to the west and downwards, the face was almost entirely composed of altered basalt. This altered basalt was generally orthogonally jointed, with some persistent defects being noted within the face, generally dipping at $30^{\circ}$ to $40^{\circ}$ to the west. A potential shear plane was also noted near the crest, again apparently dipping out of the face. Joint planes were observed to be stained to clean, smooth to rough, planar and tight.

Groundwater was not observed within the face. The standing groundwater level appeared to be roughly the level of the water ponding in the goodbye cut at the base of the quarry approximately $277 \mathrm{mRL}$.

Two slit trenches were excavated through the area of cracking at the crest. In general, the cracking appeared to be located within the vicinity of the contact between altered basalt and the weathered sandstone and residual sandy clay.

A typical view of the exposed cutting on the eastern side of the quarry is shown in Figure 6.

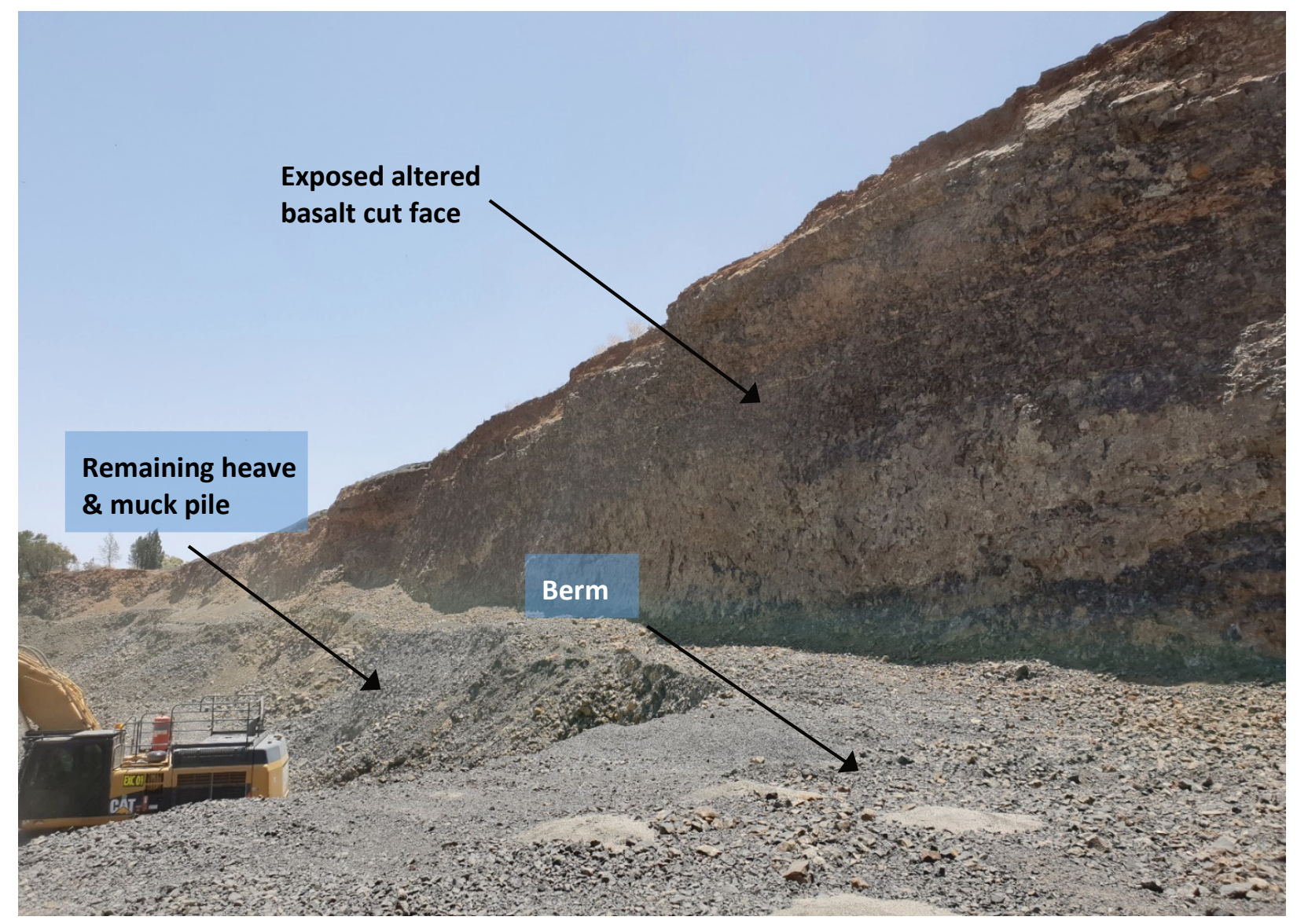

Figure 6 A typical view of the exposed cutting on the eastern side

\subsection{Slope stability analysis}

Slope stability analyses have been conducted using Slope/W (GeoStudio 2018, version 9.0.4.15639) and adopting the Morgenstern-Price method combined with both probabilistic approach and sensitivity analysis over a range of plausible geotechnical parameters. The analysis was carried adopting the following methodology:

1. Assumed that no surcharge load is applied during the simulation as the road had been closed since cracks were observed.

2. Perform slope stability analyses to establish Factors of Safety (FoS) of the slope considering cracks as result of lateral movement of the ground. 


\section{Results of slope stability analysis and discussion}

\subsection{Geological units and descriptions}

The inferred relevant geological units and their description is summarised in Table 1.

Table $1 \quad$ Summary of stratigraphic units encountered within the site

\begin{tabular}{ll}
\hline Unit & Description \\
\hline Alkali basalt (Tb) & $\begin{array}{l}\text { Fine-grained alkali basalt with some tholeiite, basanite, nephelinite, limburgite, } \\
\text { and trachyte as part of the undifferentiated Tertiary Cainozoic units. }\end{array}$ \\
Altered basalt & $\begin{array}{l}\text { This is the chilled transition zone between the basalt deposition due to lava flow } \\
\text { and its contact to the lithic sandstone. }\end{array}$ \\
Sandstone (Ju) & $\begin{array}{l}\text { Fine to medium grained lithic quartz sandstone with ferruginised red siltstone, } \\
\text { ironstone, minor coal ironstone. This Jurassic Purlawaugh Formation is part of the } \\
\text { Surat Basin of the Great Australian Basin. } \\
\text { Loose rock }\end{array}$ \\
\hline
\end{tabular}

\subsection{Geotechnical model}

The assumed geotechnical parameters for batter slope stability is presented in Table 2. The geotechnical parameters were back-estimated from the site observations combined with engineering judgement derived from prior experience in similar ground conditions. Sensitivity analyses were also carried out to account for the likely material variability.

Table 2 Assumed geotechnical parameters for batter slope stability

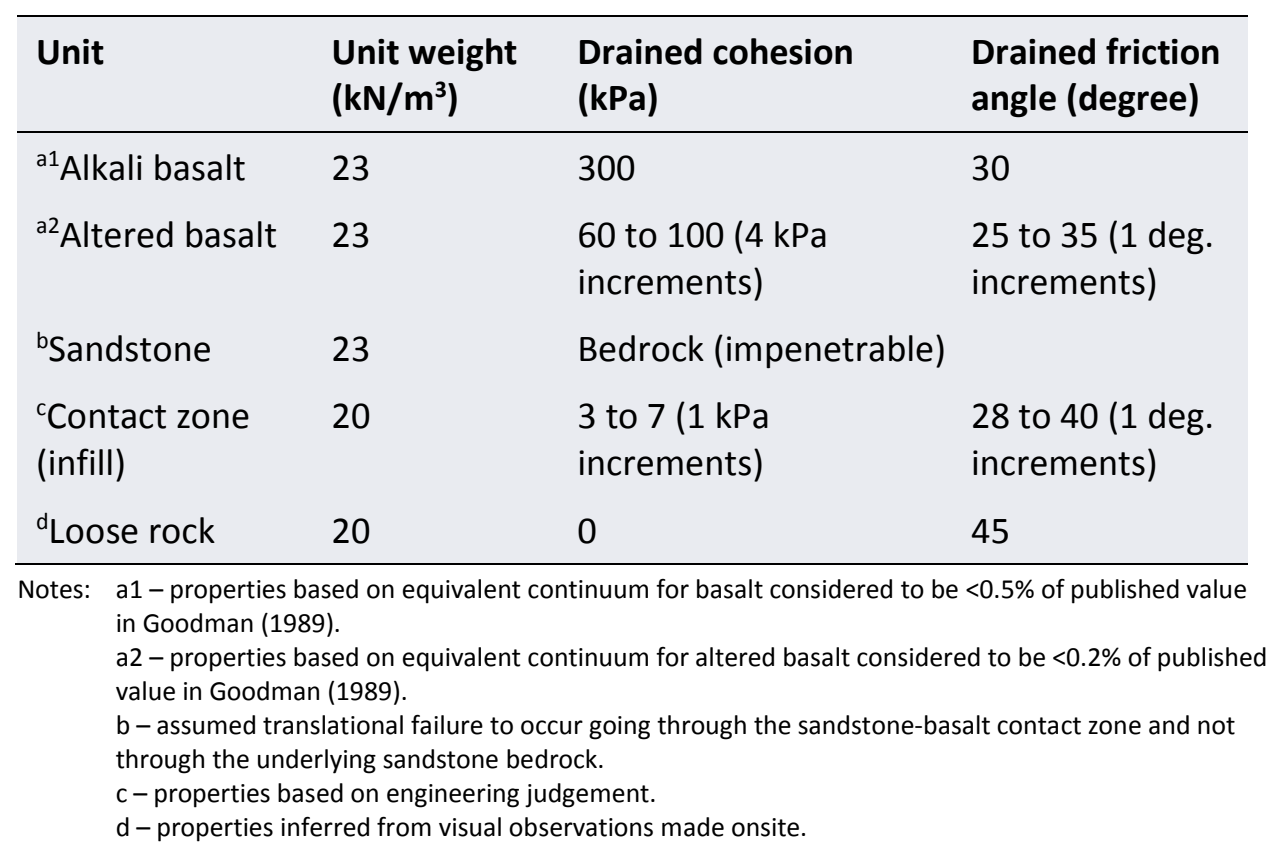

\subsection{Slope stability analysis}

The geometry presented in Figure 2 including the location of the observed tension cracking and the inferred geological boundaries and transition zones have been adopted in the slope stability analysis. The analysis involved sensitivity analysis encompassing the range and increments of drained Mohr-Coulomb strength parameters presented in Table 2. To factor in the series of rainfall events that occurred prior to the failure of 
the highwall, the groundwater level was elevated that could potentially soak up the altered basalt and the altered basalt-sandstone contact zone.

The result of the analysis indicates that with the high groundwater level and reduced strength within the contact zone and the altered basalt, the highwall would fail $(F o S<1.0)$ through an adversely sloping failure plane at the altered basalt-sandstone contact zone (Figure 7).

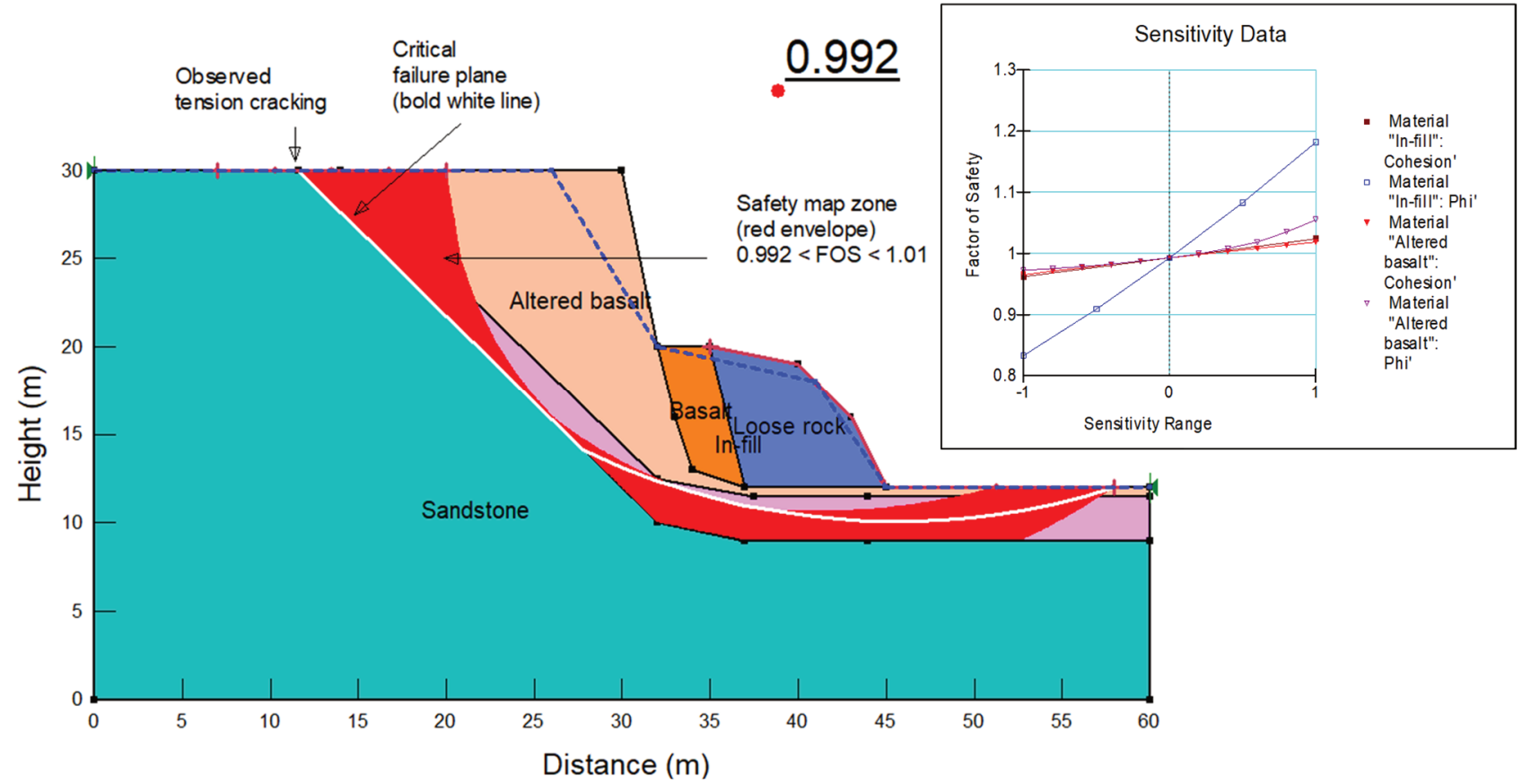

Figure 7 Result of the limit equilibrium slope stability analysis (with inset sensitivity analysis plot) of a typical highwall geometry

Based on the sensitivity analysis plot (inset in Figure 7), the stability is much more sensitive to changes in the infill friction angle. The impact to the stability of the changes in the infill cohesion and altered basalt cohesion and friction angle are somewhat similar. For the slope to be about the meta-stable state (i.e. FoS of unity), the strength parameters for both the infill and altered basalt materials need to be two increments above their average values as provided in Table 2.

\subsection{Details of the highwall failure}

On 8 February 2019, the eastern highwall failure slid down approximately four metres. The area of failure was roughly $80 \mathrm{~m}$ in length, and up to $20 \mathrm{~m}$ in width, between prisms no. 75 and 175 . A general view of the failed highwall is shown in Figure 8.

The prisms within this area (nos. 85, 100, 125 and 150) had recorded the greatest movement to the east (-ve) during the period of monitoring, and had also shown an acceleration in easterly movement in the ten days beforehand. The back scarp of the failure did not reveal the lithic sandstone of the footwall, but observations of the failed material on 9 February confirmed that it was due to translational-planar failure along the altered basalt-sandstone contact zone. The geometry post failure was assessed to have marginal stability and Factor of Safety close to unity, but cannot be readily quantified due to limited understanding of the sub-surface failure profile and the altered strength parameters. 


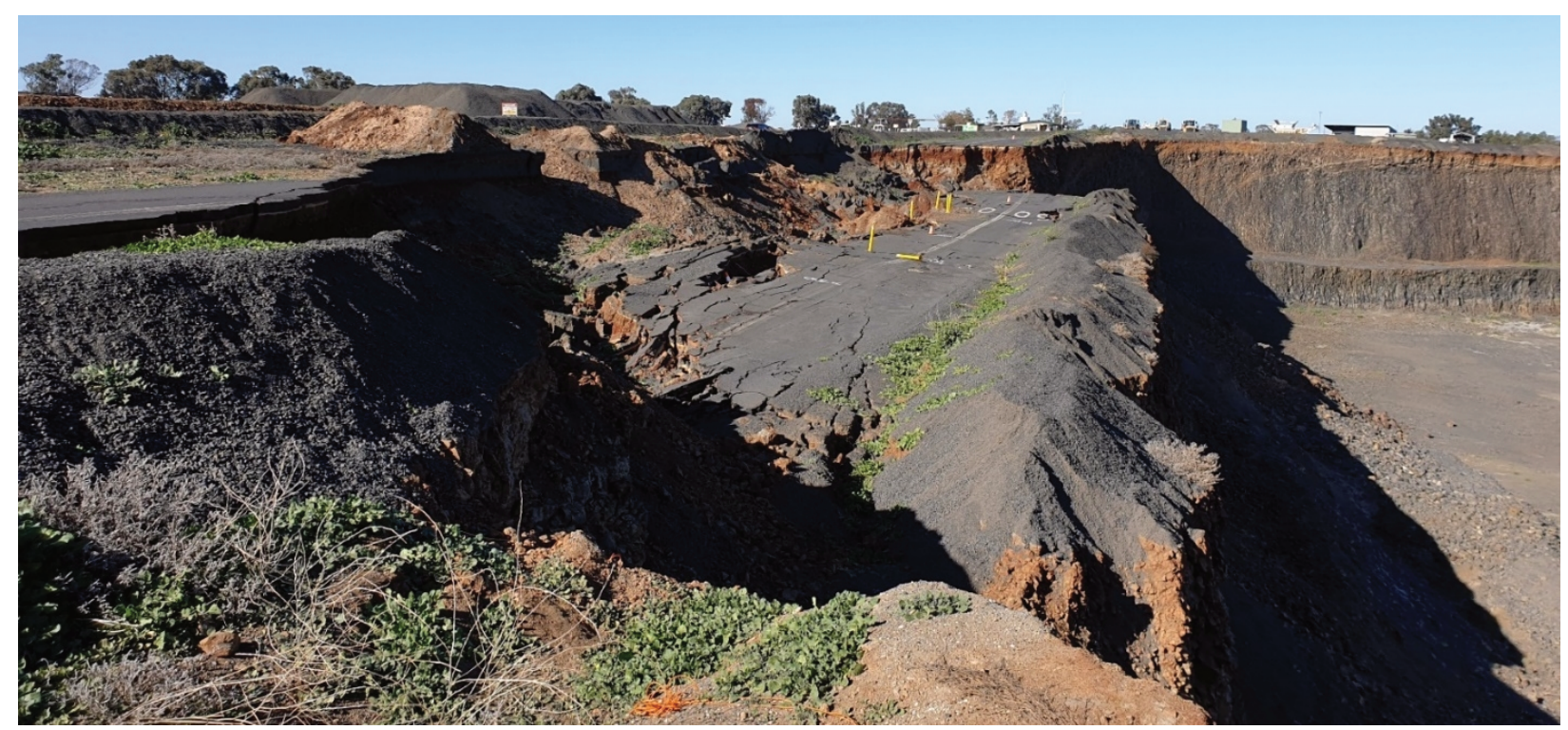

Figure $8 \quad$ View of the failed highwall on the eastern side of the quarry

\section{Conclusion}

This paper presents a case study illustrating the use of readily available data such as point measurement data derived from traditional geodetic prism monitoring, visual field observations, review of geological background information and a simplified wedge stability analysis via limit equilibrium methods in the assessment of rock slope performance on open pit mine highwalls. The study focuses on the compounding evidence that a highwall failure is imminent.

The study demonstrates how a series of relatively simple approach combined with sound engineering judgement can be used to describe the likely failure mechanism present along a rock slope and to highlight the presence of potential instabilities.

Noting the approximately $20 \mathrm{~m}$ lateral (east-west) extent of the collapse is very close to the observed location of the tension cracking at $18 \mathrm{~m}$ away from the original cutting crest, it would appear that the adopted simplified analytical methodology based on observed displacements, in combination with a good understanding of the geologic setting, can be used to predict likely performance of cut faces in weak transition rocks. This approach can be used more frequently in the industry, especially for the characterisation of rock slope in challenging environment.

\section{Acknowledgement}

GHD gratefully acknowledge the support and cooperation of Holcim (Australia) Pty Ltd, and in particular the Dubbo Quarry Manager Alasdair Webb, including permission to publish this paper.

\section{References}

Goodman, RE 1989, Introduction to Rock Mechanics, John Wiley \& Sons, New York.

Mathis, JI 2007, 'Pit slope design and structural analysis at the Jericho Diamond Mine utilising digital photogrammetric mapping', in Y Potvin (ed.), Proceedings of the International Symposium on Rock Slope Stability in Open Pit Mining and Civil Engineering 2007, Australian Centre for Geomechanics, Perth, pp. 93-104.

Mathis, JI 2011, 'Photogrammetry discontinuity mapping as applied to structural interpretation and drillhole planning at Barrick's Williams Pit', Proceedings of the International Symposium on Rock Slope Stability in Open Pit Mining and Civil Engineering (Slope Stability 2011), Canadian Rock Mechanics Association, CD only.

Read, J \& Stacey, P 2009, Guidelines for Open Pit Slope Design, CSIRO Publishing, Collingwood. 
